\title{
(2) Efficacy and cardiovascular safety of LAMA in OPEN ACCESS patients with COPD: a systematic review and meta-analysis
}

\author{
Chuchu Zhang, ${ }^{1,2}$ Meng Zhang, ${ }^{1,2}$ Yalei Wang, ${ }^{1,2}$ Huaiyu Xiong, ${ }^{1,2}$ \\ Qiangru Huang, ${ }^{1,2}$ Tiankui Shuai, ${ }^{1,2}$ Jian Liu (1)
}

Additional supplemental material is published online only. To view, please visit the journal online (http://dx. doi.org/10.1136/jim-2021 001931).

'Department of Intensive Care Unit, Lanzhou University First Affiliated Hospital, Lanzhou, Gansu, China

${ }^{2}$ The First Clinical Medical College of Lanzhou University, Lanzhou University, Lanzhou, Gansu, China

\section{Correspondence to} Dr Jian Liu, Department of Intensive Care Unit, Lanzhou University First Affiliated Hospital, Lanzhou University, Lanzhou, Gansu 730000,

China; medecinliu@sina.com

Accepted 13 July 2021

\section{ABSTRACT}

Chronic obstructive pulmonary disease (COPD) is at present the third leading cause of death in the world. Long-acting muscarinic antagonist (LAMA) is widely used as a bronchodilator in patients with COPD. However, there is controversy concerning their cardiovascular safety. This meta-analysis aims to assess the efficacy and cardiovascular safety of LAMAs versus placebo in patients with COPD. We searched Pub Med, Embase, Cochrane Library, and Web of Science to identify studies that compared LAMA with placebo in patients with COPD.

Twenty-one studies involving 24,987 participants were finally included in the analysis. There was no significant difference in the incidence of all adverse events (risk ratio $(R R)=1.01,95 \% \mathrm{Cl} 1.00$ to 1.02 , $\left.I^{2}=15.2 \%\right)$ and cardiovascular events ( $R R=0.98$, $95 \% \mathrm{Cl} 0.88$ to $1.09, \mathrm{I}^{2}=4.9 \%$ ) in patients treated with LAMAs versus placebo. LAMAs significantly improved trough forced expiratory volume in $1 \mathrm{~s}$ (weighted mean difference (WMD) $=0.12,95 \% \mathrm{Cl}$ 0.10 to $\left.0.14, I^{2}=86.6 \%\right)$, Transitional Dyspnea Index (WMD $=0.75,95 \% \mathrm{Cl} 0.56$ to $0.94, \mathrm{I}^{2}=0 \%$ ), and St. George's Respiratory Questionnaire (WMD $=-2.50$, $95 \% \mathrm{Cl}-3.32$ to $\left.-1.69, \mathrm{I}^{2}=39.8 \%\right)$. Moreover, LAMAs significantly reduced the incidence of exacerbation in patients with COPD (RR $=0.85$, $95 \% \mathrm{Cl} 0.79$ to $0.91, \mathrm{I}^{2}=69.9 \%$ ). LAMAs are safe therapy and play a pivotal role in improving lung function, dyspnea, and health status, and reducing the exacerbation in patients with COPD.

\section{INTRODUCTION}

Chronic obstructive pulmonary disease (COPD) is a preventable and treatable disease that is characterized by persistent respiratory symptoms and airflow limitation. According to the top 10 causes of death released by the WHO on May 24, 2018, it is the third leading cause of death in the world. ${ }^{1-3}$ The bronchodilator is the cornerstone in the treatment of patients with COPD. ${ }^{1}$ Long-acting muscarinic antagonist (LAMA) is one of the bronchodilators, containing glycopyrronium, umeclidinium, aclidinium, tiotropium, and revefenacin. ${ }^{4}$ Besides, LAMAs are recommended for patients with COPD in Global Initiative for Chronic Obstructive Lung Disease groups A-D. ${ }^{15}$
Although LAMAs are widely used for maintenance bronchodilation in patients with COPD, ${ }^{1}$ there is controversy regarding their cardiovascular safety. ${ }^{6-11}$ Dong et al reported that tiotropium had a higher risk of mortality compared with other inhaled medications. ${ }^{8}$ Similarly, Singh et al demonstrated that inhaled anticholinergics are associated with a significantly increased risk of cardiovascular mortality. ${ }^{12}$ However, several large clinical randomized controlled trials (RCTs) regarding LAMA in patients with COPD reported that there was no increasing risk in major adverse cardiovascular events (MACEs), which indicated a composite of cardiovascular death, non-fatal myocardial infarction (MI), and non-fatal stroke. ${ }^{9} 1314$ Furthermore, Wise et al recently carried out a 3-year large RCT to assess the cardiovascular safety and efficacy of aclidinium in patients with COPD and found no increased risk in MACE compared with placebo. ${ }^{15}$

Also, it is a pivotal issue to assess the effect of LAMA versus placebo on relevant outcomes of patients with COPD. However, high-quality meta-analyses available did not include the recently published large RCTs. ${ }^{15} 16$ Moreover, they included a single LAMA whereas did not conduct a general analysis of different LAMAs. ${ }^{17-19}$

Accordingly, this meta-analysis aimed to determine the efficacy and cardiovascular safety of LAMA. We assessed the cardiovascular safety of LAMA based on all adverse events (treatment emergent and other adverse events) and expand MACE that defined as MACE and other serious cardiovascular events (such as acute heart failure, life-threatening arrhythmias and so on). Lung function, dyspnea symptoms, and healthrelated quality of life (HRQoL) were used to evaluate the efficacy of LAMA. Furthermore, we expected this meta-analysis to provide more precise evidence for the clinical use of LAMAs.

\section{METHODS}

This systematic review methodology complies with the Preferred Reporting Items for Systematic Reviews and Meta-Analyses Statement guidance. ${ }^{20}$ It is based on a protocol that was 
registered in the PROSPERO register of systematic reviews (CRD42020163598).

\section{Literature search}

We searched Pub Med, Embase, Cochrane Library, and Web of Science from inception to December 2019 (update on March 2021), to identify RCTs that compared LAMA versus placebo in patients with COPD. There was no restriction about language or population. We checked reference lists of all studies that were identified by the above-mentioned searches. Also, the ClinicalTrials.gov database was searched for the completed eligible study. The following keywords were used in our search: long-acting muscarinic antagonists (glycopyrronium, umeclidinium, aclidinium, tiotropium, revefenacin), chronic obstructive pulmonary disease, and RCT. The detailed search strategy was shown in the online supplemental file 1.

\section{Inclusion and exclusion criteria Inclusion criteria}

- Studies which were placebo-controlled, parallel-group RCT with at least 8 weeks' duration, in patients with COPD confirmed by spirometry, comparing the efficacy and safety of LAMA with placebo.

- Studies were required to report at least one of the following outcomes: all adverse events, expand MACE (including coronary artery disease: MI, angina, angioplasty/stent/coronary artery bypass graft; peripheral vascular disease: history of claudication; or cerebrovascular disease: stroke or transient ischemic attack, carotid stenosis), trough forced expiratory volume in $1 \mathrm{~s}$ (trough $\mathrm{FEV}_{1}$ ), HRQoL assessed with the St. George's Respiratory Questionnaire (SGRQ), symptoms (dyspnea) assessed with the Mahler Transitional Dyspnea Index focal score (TDI), and COPD exacerbation.

\section{Exclusion criteria}

- Studies that described LAMA treatment on other lung disease, such as asthma, obstructive sleep apnea hypopnea syndrome, acute respiratory distress syndrome, and asthma-COPD overlap.

- Studies that researched animals or cells.

- Studies that are conference abstracts, letters, editorials, reviews, and meta-analyses.

\section{Study selection and data extraction}

Two authors (CCZ and MZ) reviewed the search results for relevant article titles meeting the inclusion criteria. All titles screening and full-text eligibility assessment were performed by one of the authors (CCZ), the references that did not meet the eligibility criteria were excluded. Another reviewer reassessed and validated study selection (MZ). Minor disagreements were settled by discussion. Data from each study were extracted by one author (CCZ) and validated by a second author (MZ) in exhaustive tabulated data extraction forms, with a cross-check against the original papers. For every study included, the following data were extracted: participant (sample size, mean age, gender, and current smoker), intervention (drug, inhaler, dosage, and frequency), outcomes (all adverse events, cardiovascular events, trough $\mathrm{FEV}_{1}$, SGRQ score, TDI score, and exacerbation), and design (authors, location, publication year, study design, and duration of follow-up).

\section{Assessment of risk of bias in included studies}

We assessed the quality following 6 points outlined in the Cochrane Handbook for Systematic Reviews of Interventions, which included random sequence generation (selection bias), allocation concealment (selection bias), blinding (performance bias and detection bias), incomplete outcome data (attrition bias), selective outcome reporting (attrition bias) and other potential sources of bias. The criteria to grade included studies were as follows: (1) trials were graded as low quality if either randomization or allocation concealment was assessed as a high risk of bias, regardless of other items; (2) trials were graded as high quality when both randomization and allocation concealment were assessed as a low risk of bias, and all other items were assessed as low or unclear risk of bias in a trial; (3) trials were graded as moderate quality if they did not meet criteria for high or low risk. The risk of bias was assessed by two reviewers independently (HX and YW) and the discrepancy was solved by consulting an evidence-based medicine professor.

\section{Data analysis}

Stata/SE V.15.0 was used to perform all data analyses. We explained the metric of analysis for outcomes as the following: risk ratios (RRs) and their associated 95\% CIs were used as the effective measures for the outcomes of dichotomous data. Weighted mean difference (WMD) and the corresponding $95 \% \mathrm{CI}$ were used for continuous outcomes. We used $\mathrm{p}$ value and $\mathrm{I}^{2}$ statistic to measure heterogeneity among the trials in each analysis. The fixed or random effect models were used without important heterogeneity $\left(\mathrm{I}^{2}<50 \%\right)$ or with moderate heterogeneity $\left(\mathrm{I}^{2} \geq 50 \%\right)$, respectively. We performed a subgroup analysis to analyze any possible source of heterogeneity when the heterogeneity was high. A sensitivity analysis was performed to detect if the results were stable and reliable. If there were 10 or more publications, a funnel plot, Egger's test, and Begg's test were used to assess publication bias. ${ }^{21} 22$

\section{RESULT}

\section{Eligible studies and risk of bias}

We obtained 3565 records from four databases and other sources, and 2463 remained after deduplication. Full texts of 108 records were read, of which 32 RCTs from 29 records met the eligibility criteria and were included in the final meta-analysis. ${ }^{14-16} 23-48$ There were 3 articles that each reported 2 RCT studies. ${ }^{23} 290$ The 32 RCTs included 29,857 participants, of whom 16,548 received LAMA and 13,309 received placebo. ${ }^{14-16} 23-39$ The selection process was shown in figure 1. In eligible studies, 18 RCTs were high-quality studies. The risk of bias in the 6 items of the Cochrane instrument was shown in the online supplemental figures S1 and S2.

\section{Description of included studies}

We listed specific characteristics of included studies in online supplemental table S1. All included studies were randomized, double-blind, placebo-controlled trials. In eligible studies, 6 RCTs studied aclidinium versus placebo 


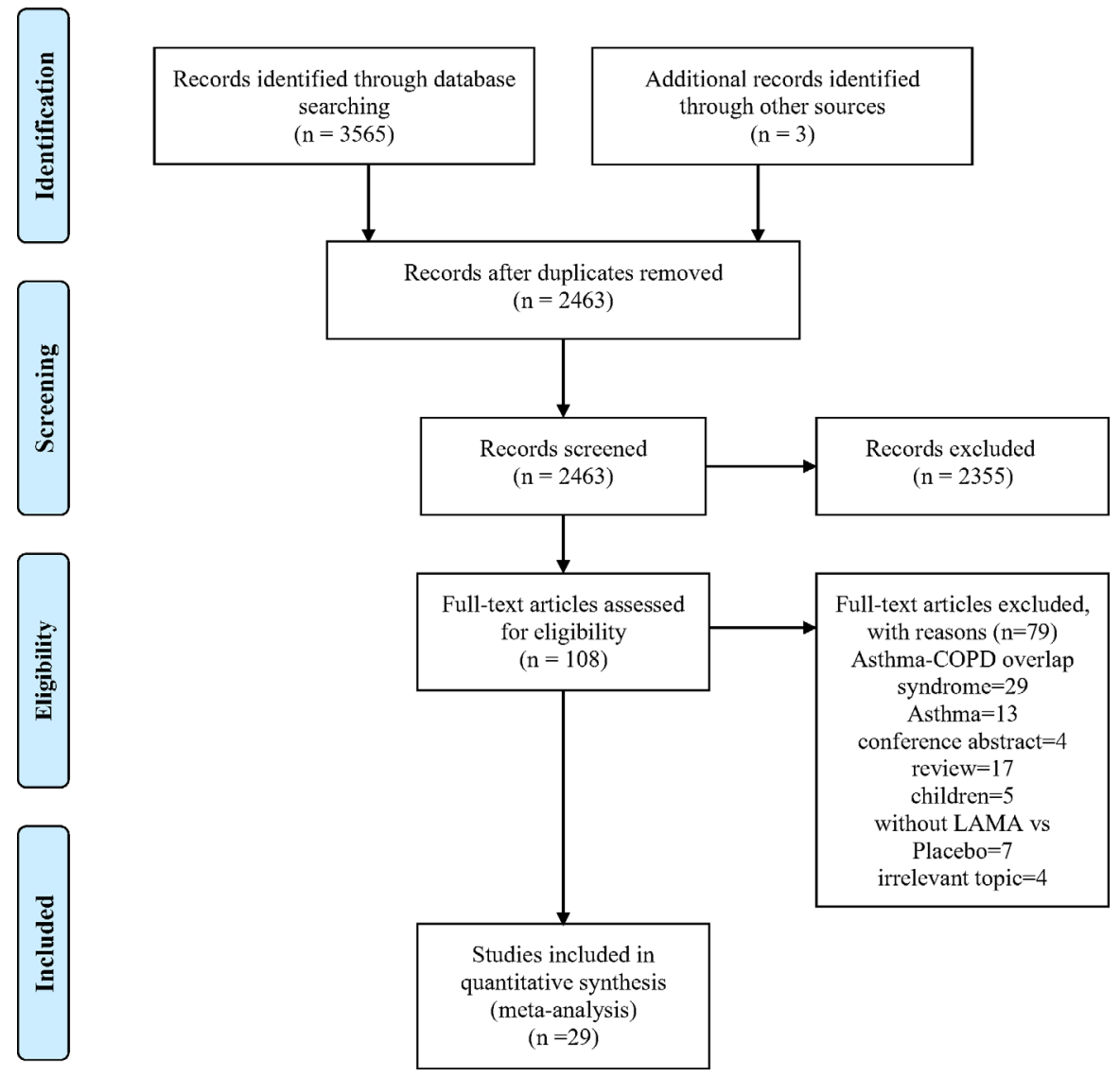

Figure 1 Study selection process: PRISMA flow diagram identifying studies included in the meta-analysis. COPD, chronic obstructive pulmonary disease; LAMA, long-acting muscarinic antagonist; PRISMA, Preferred Reporting Items for Systematic Reviews and MetaAnalyses.

in patients with COPD. ${ }^{15252628} 29$ The dosage of aclidinium was $200 \mu \mathrm{g}$ once daily or $400 \mu \mathrm{g}$ two times per day. There were 7 RCTs that described glycopyrronium which was administrated as $50 \mu \mathrm{g}$ once daily, $18 \mu \mathrm{g}$ two times per day or $15.6 \mu \mathrm{g}$ two times per day. ${ }^{23} 2427304145$ Eleven RCTs assessed tiotropium $5 \mu \mathrm{g}, 10 \mu \mathrm{g}$, or $18 \mu \mathrm{g}$ two times per day on administrating patients with COPD. ${ }^{14} 16$ 31-39 Six RCTs reported umeclidinium $62.5 \mu \mathrm{g}$ or $125 \mu \mathrm{g}$ once daily in patients with COPD. ${ }^{42-44} 46-48$ Also, revefenacin $175 \mu \mathrm{g}$ once daily on patients with COPD was reported by 2 RCTs which was contained in 1 article. $^{40}$

\section{Effect of treatments on safety outcomes}

In eligible studies, 32 RCTs reported all adverse events. ${ }^{14-16} 23-48$ There were no significant differences in the incidence of all adverse events of patients with LAMA versus those with placebo $(\mathrm{RR}=1.01,95 \% \mathrm{CI} 1.00$ to 1.02 , $I^{2}=15.2 \%$, figure 2). Similarly, 23 RCTs described cardiovascular events (expand MACE) ${ }^{14-16} 232426-32384042-47$ and we found no higher increase risk of cardiovascular events in patients with COPD with LAMA versus placebo $(\mathrm{RR}=0.98$, $95 \%$ CI 0.88 to $1.09, \mathrm{I}^{2}=4.9 \%$, figure 3 ). Furthermore, considering that the duration of included studies varied from 8 to 192 weeks, we conducted subgroup analysis based on the duration. The results indicated that there was no increased risk in all adverse events and cardiovascular events in patients with COPD receiving LAMA compared with those receiving placebo (online supplemental figures S3 and S4).

\section{Effect of treatments on trough FEV}

We evaluated the improvement of lung function by the change of trough FEV from baseline. Twenty-four RCTs reported trough $\mathrm{FEV}_{1}{ }^{23-27} \quad 30-35 \quad 39 \quad 41-44 \quad 46-48$ Overall, LAMA was proved to be superior to placebo in all studies $\left(\mathrm{WMD}=0.12,95 \% \mathrm{CI} 0.10\right.$ to $0.14, \mathrm{I}^{2}=86.6 \%$, figure 4 ). As for the heterogeneity, we performed subgroup analysis based on the type of LAMA, the treatment duration, and the inhaler of LAMA, which indicated that they are not the main sources of the heterogeneity (online supplemental figures S5-S7).

\section{Effect of treatments on dyspnea and HRQoL (TDI, SGRQ)}

The effect of treatment on dyspnea and HRQoL was assessed by TDI and SGRQ, respectively. Nine RCTs measured the TDI score from baseline and indicated that LAMA led to significant improvement in TDI compared with placebo (WMD $=0.75,95 \% \mathrm{CI} 0.56$ to $0.94, \mathrm{I}^{2}=0 \%$, online supplemental figure S8). ${ }^{23} 25-2830414647$ Thirteen RCTs reported TDI responders, indicating that more participants receiving LAMA had a clinically meaningful difference in TDI score compared with placebo $(\mathrm{RR}=1.29$, $95 \%$ CI 1.23 to $1.35, \mathrm{I}^{2}=0 \%$, online supplemental figure 


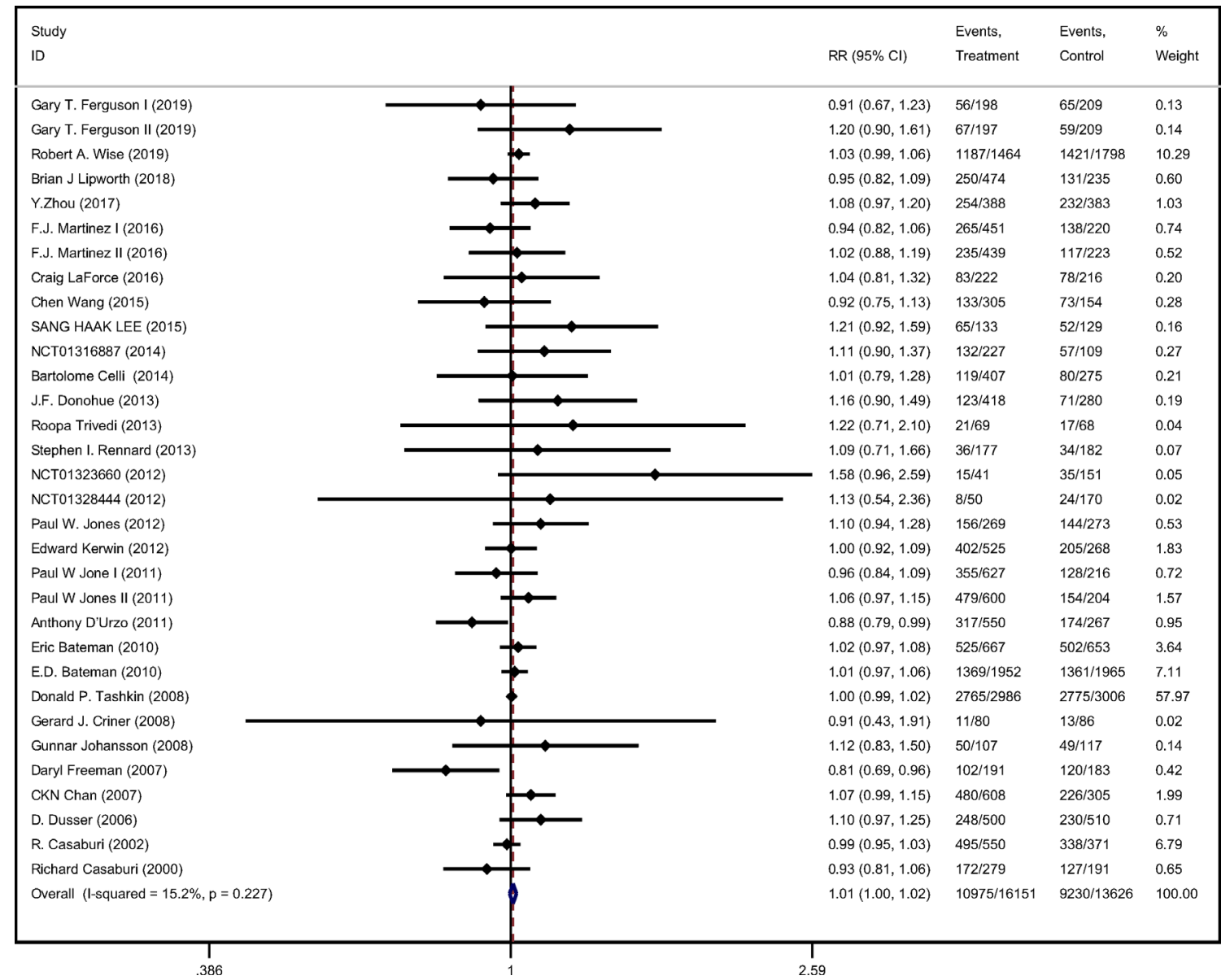

Figure 2 Forest plot of all adverse events in patients with COPD with LAMAs versus placebo. COPD, chronic obstructive pulmonary disease; LAMA, long-acting muscarinic antagonist; RR, risk ratio.

S9). ${ }^{23-3032414647}$ Likewise, 9 RCTs reported SGRQ and demonstrated that LAMA was associated with an improved quality of life compared with placebo (WMD $=-2.50$, $95 \% \mathrm{CI}-3.32$ to $-1.69, \mathrm{I}^{2}=39.8 \%$, online supplemental figure S10). ${ }^{23} 25-2730414547$ More participants with LAMA had a clinically meaningful difference in SGRQ compared with placebo $\left(\mathrm{RR}=1.23,95 \% \mathrm{CI} 1.19\right.$ to $1.27, \mathrm{I}^{2}=0 \%$, online supplemental figure S11). ${ }^{143-323638404145-47}$

\section{Effect of treatments on COPD exacerbation}

Nineteen RCTs reported the number of patients with at least one moderate or severe exacerbation. The metaanalysis results indicated that LAMA reduced the incidence of COPD exacerbation over placebo $(\mathrm{RR}=0.85$, $95 \%$ CI 0.79 to $0.91, \mathrm{I}^{2}=69.9 \%$, online supplemental figure S12). $.^{14-16} \quad 2324 \quad 26-34 \quad 36-3841$ The subgroup analysis showed that glycopyrronium had a more significant effect on reducing the number of patients with at least one moderate or severe exacerbation (online supplemental figure S12). Besides, due to the inconsistency of the duration, we performed subgroup analysis based on the duration which indicated that LAMAs did decrease the exacerbation of patients with COPD (online supplemental figure S13).

\section{Sensitivity analysis and publication bias}

As for the safety outcome (including all adverse events and cardiovascular events), the results of the sensitivity analysis did not change after removing the included studies one by one (online supplemental figures S14 and S15). With regard to the efficacy outcome of trough $\mathrm{FEV}_{1}$ and the reduction of COPD exacerbation, the results of the sensitivity analysis remained consistent after excluding the studies one by one (online supplemental figures S16 and S17, online supplemental table S2). The Egger's test and the Begg's test both indicated that there was no significant publication bias (Egger's test, $\mathrm{p}=0.337$; Begg's test, $\mathrm{z}=0.92, \mathrm{p}=0.355$ ). The result of the funnel plot was shown in online supplemental figure S18.

\section{DISCUSSION}

Based on the findings of this systematic review and metaanalysis, LAMA is an effective and safe treatment for patients with COPD. There was no significant difference observed in all adverse events (treatment emergent and other adverse events) and cardiovascular events between LAMA and placebo group. Also, LAMA led to conspicuous improvements in lung function, HRQoL (SGRQ), dyspnea (TDI), and a reduction in the number of patients with COPD exacerbation. 


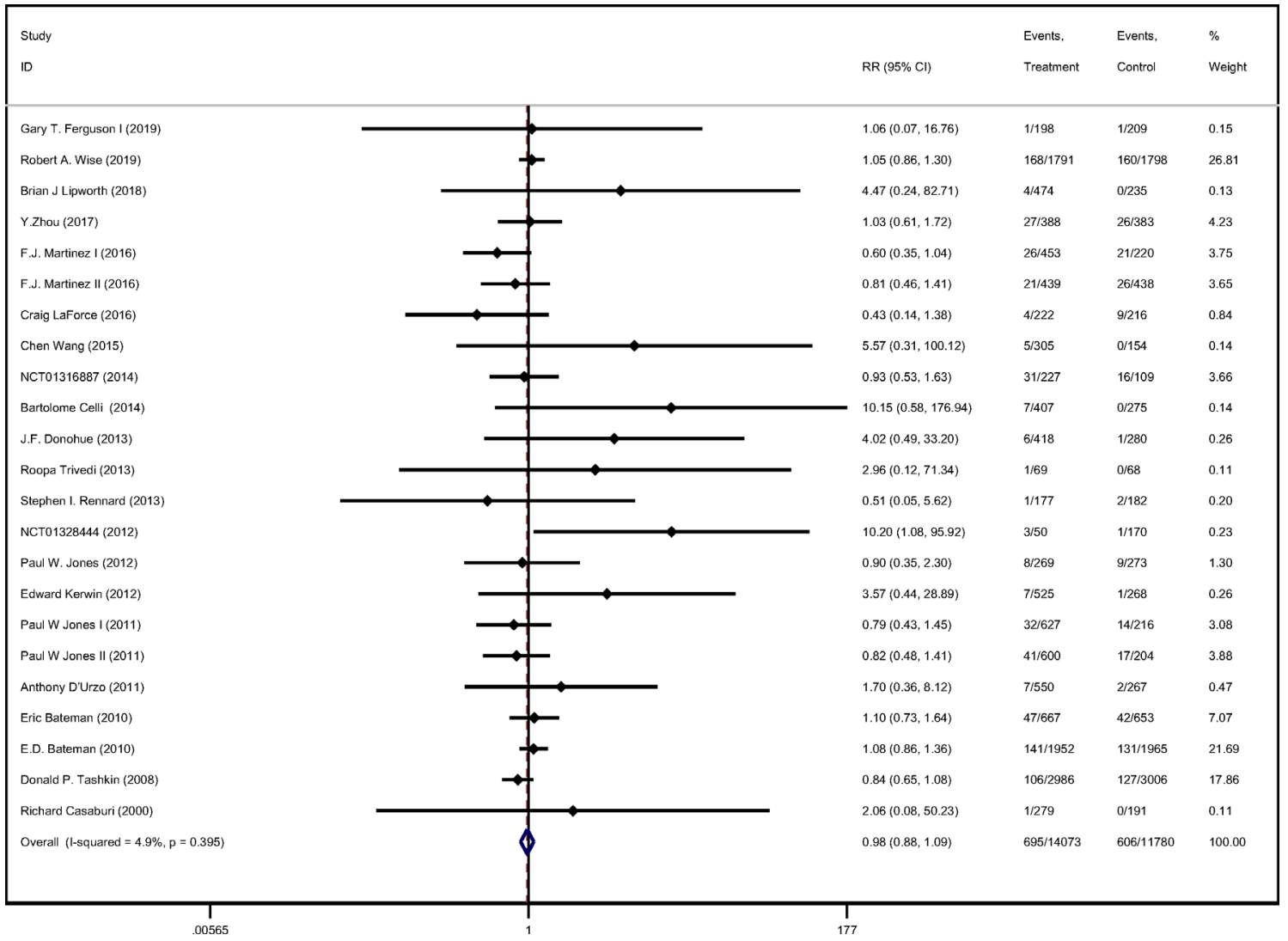

Figure 3 Forest plot of cardiovascular events in patients with COPD with LAMAs versus placebo. COPD, chronic obstructive pulmonary disease; LAMA, long-acting muscarinic antagonist; RR, risk ratio.

The results of this meta-analysis revealed that LAMA is a cardiovascular safe therapy for patients with COPD compared with placebo based on current evidence. In contrast, a meta-analysis by Singh et al ${ }^{12}$ reported that inhaled anticholinergics are associated with a significantly increased risk of cardiovascular death, MI, or stroke among patients with COPD. The meta-analysis included clinical trials regarding ipratropium, which is one of the short-acting muscarinic antagonists. However, the subgroup analysis indicated that tiotropium was not associated with higher cardiovascular risk compared with placebo $\left(\mathrm{RR}=1.43,95 \% \mathrm{CI} 0.95\right.$ to $\left.2.16, \mathrm{I}^{2}=0 \%\right)$. This meta-analysis was later considered with several methodology limitations, such as potential study selection bias, which was limited to trials reporting cardiovascular events; lack of assessment of patient follow-up time and so on. ${ }^{13}$ As for several clinical trials reported that ipratropium was associated with increased risk of cardiovascular events or death, these studies are retrospective analyses and there are inherent limitations and problems that preclude definitive conclusion. ${ }^{49}$ Thus, the result actually is consistent with our findings. Also, a post hoc study of tiotropium found no increased risk in patients with recent cardiovascular events. ${ }^{50}$ Similarly, a pooled analysis of aclidinium found no evidence of increased cardiovascular risk with aclidinium versus placebo. ${ }^{51}$ On the other hand, observational studies also reported conflicting results. ${ }^{10}$ This discrepancy can be explained with the exclusion of patients who have cardiovascular comorbidities and renal impairment in clinical trials. ${ }^{52}{ }^{53}$ Consequently, more high-quality RCTs assessing the safety of LAMAs which specifically enrolled patients with increased cardiovascular risk are needed in the future.

This meta-analysis demonstrated that LAMAs were associated with significant improvement in lung function compared with placebo. LAMAs led to a greater improvement in trough $\mathrm{FEV}_{1}$ of between $100 \mathrm{~mL}$ and $140 \mathrm{~mL}$ over placebo. This has the physiological rationality: antimuscarinic drugs block the bronchoconstrictor effects of acetylcholine on M3 muscarinic receptors expressed in airway smooth muscle; LAMAs have prolonged binding to M3 muscarinic receptors, thus prolonging the duration of bronchodilator effect. ${ }^{4}$ The result was consistent with several meta-analyses that studied the safety and efficacy of aclidinium or tiotropium. ${ }^{17} 19$

The results found in lung function were paralleled with significant improvements in the SGRQ score and TDI focal score. Mean differences in SGRQ reduction between LAMA and placebo observed in our analysis were between 1.69 and 3.32 units. The minimal clinically important difference for SGRQ score is 4 units. ${ }^{54}$ The mean differences were not reached to 4 units, but the probability of having a response superior to 4 units was significantly increased by $23 \%$ versus placebo. The mean difference in TDI score improvement was observed as $0.56-0.94$ units. The minimal clinically important difference for TDI score is 1 unit. ${ }^{55}$ Patients with LAMAs had a $29 \%$ higher probability to experience an improvement $>1$ unit in the TDI dyspnea score versus patients treated with placebo. The results are consistent 


\begin{tabular}{|c|c|c|c|}
\hline $\begin{array}{l}\text { Study } \\
\text { ID }\end{array}$ & & WMD $(95 \% \mathrm{Cl})$ & $\begin{array}{l}\% \\
\text { Weight }\end{array}$ \\
\hline Gary T. Ferguson I (2019) & $1 \quad \longrightarrow$ & $0.21(0.17,0.24)$ & 4.93 \\
\hline Gary T. Ferguson II (2019) & & $0.15(0.10,0.20)$ & 4.16 \\
\hline Brian J Lipworth (2018) & -1 & $0.11(0.07,0.14)$ & 4.84 \\
\hline F.J. Martinez I (2016) & & $0.09(0.05,0.13)$ & 4.73 \\
\hline F.J. Martinez II (2016) & $\longrightarrow$ & $0.05(0.01,0.09)$ & 4.72 \\
\hline Craig LaForce (2016) & & $0.12(0.08,0.16)$ & 4.52 \\
\hline Chen Wang (2015) & & $0.16(0.12,0.20)$ & 4.61 \\
\hline Sang Haak Lee (2015) & & $0.13(0.02,0.23)$ & 2.35 \\
\hline NCT01316887 (2014) & & $0.18(0.08,0.28)$ & 2.56 \\
\hline Bartolome Celli (2014) & & $0.16(0.12,0.20)$ & 4.70 \\
\hline J.F. Donohue (2013) & 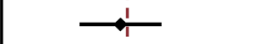 & $0.12(0.08,0.15)$ & 4.65 \\
\hline Roopa Trivedi (2013) & & $0.15(0.08,0.23)$ & 3.30 \\
\hline Stephen I. Rennard (2013) & 1 & $0.07(0.03,0.11)$ & 4.52 \\
\hline NCT01323660 (2012) & I & $0.25(0.19,0.32)$ & 3.73 \\
\hline NCT01328444 (2012) & 1 & $0.14(0.08,0.20)$ & 3.91 \\
\hline Paul W. Jones (2012) & & $0.13(0.08,0.17)$ & 4.47 \\
\hline Edward Kerwin (2012) & 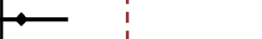 & $0.02(-0.03,0.06)$ & 4.45 \\
\hline Anthony D'Urzo (2011) & $\curvearrowleft$ & $0.01(-0.03,0.04)$ & 4.89 \\
\hline E.D. Bateman (2010) & & $0.10(0.08,0.12)$ & 5.26 \\
\hline Eric Bateman (2010) & $\leftarrow$ & $0.15(0.14,0.16)$ & 5.37 \\
\hline Gunnar Johansson (2008) & & $0.12(0.06,0.18)$ & 3.79 \\
\hline Gerard J. Criner (2008) & & $0.13(0.05,0.20)$ & 3.44 \\
\hline Daryl Freeman (2007) & & $0.06(-0.13,0.25)$ & 1.10 \\
\hline Richard Casaburi (2000) & & $0.15(0.12,0.18)$ & 5.02 \\
\hline Overall $(I-$ squared $=86.6 \%, p=0.000)$ & $>$ & $0.12(0.10,0.14)$ & 100.00 \\
\hline NOTE: Weights are from random effects analysis & & & \\
\hline $\begin{array}{c} \\
.319 \\
\end{array}$ & & & \\
\hline
\end{tabular}

Figure 4 Forest plot of trough FEV in patients with COPD with LAMAs versus placebo. COPD, chronic obstructive pulmonary disease; $\mathrm{FEV}_{1}$, forced expiratory volume in $1 \mathrm{~s}$; LAMA, long-acting muscarinic antagonist; WMD, weighted mean difference.

with an available meta-analysis, which suggested that all LAMAs are efficacious relative to placebo. ${ }^{56}$

Additionally, LAMAs were associated with a reduced number of patients with at least one moderate or severe exacerbation. Based on current evidence, we found that LAMAs led to a $15 \%$ lower exacerbation rate compared with placebo. The results were consistent with a metaanalysis of tiotropium which suggested that tiotropium reduced exacerbation of patients with COPD. ${ }^{18}$ Reduction in exacerbation is an overarching goal in the management of COPD. ${ }^{1}$ Thus, the finding of this meta-analysis indicates that LAMAs are effective therapy for patients with COPD.

However, the heterogeneity of lung function was high. Subgroup analysis does not effectively reduce heterogeneity. After we conducted a sensitivity analysis, the directions of effect sizes were consistent among the included trials. We considered the source of heterogeneity might be as follows: first, medicine factors (the dosage, administration device) were variable in different research. There were $200 \mu \mathrm{g}$ once daily $^{29}$ and $400 \mu \mathrm{g}$ two times per day ${ }^{15252628}$ of aclidinium usage. Regarding glycopyrronium, the included studies used $15.6 \mu \mathrm{g}$ two times per day ${ }^{23}$ or $50 \mu \mathrm{g}$ once daily. ${ }^{242730}$ There were $5 \mu \mathrm{g}$ once daily, ${ }^{32} 10 \mu \mathrm{g}$ once daily, ${ }^{31}$ and $18 \mu \mathrm{g}$ once daily $^{14} 16^{33-39}$ of tiotropium treatment. The administration device was soft mist inhaler, dry-powder inhaler, metereddose inhaler, or jet nebulizer from different manufacturers. The differences in dosage and administration device might both influence the treatment effect. Second, the treatment duration was 8-192 weeks, which might influence the heterogeneity of lung function. Third, several factors might impact the measurement of lung function, such as the tester's professional competence and the patients' education status. Finally, the patients' severity of COPD and smoking status might influence the efficacy of LAMA in improving lung function. Thus, these could also be a source of heterogeneity.

Besides, the heterogeneity is high regarding the number of patients with at least one moderate or severe exacerbation. We considered the heterogeneity source might be the diagnosis of COPD exacerbation. Exacerbation of COPD is defined as an acute worsening of respiratory symptoms that results in additional therapy. ${ }^{5758}$ However, the diagnosis of COPD exacerbation in clinical setting depends largely on the subjective judgment of the physician, which might be the source of the heterogeneity.

Finally, this meta-analysis had several limitations. First, we did not perform a detailed analysis of every adverse event due to lack of original data. Second, several endpoints such as exercise tolerance and rescue medication use were not included for the reason that there were no consistent definitions and methodology for the two endpoints across trials, precluding accurate comparisons. Finally, several studies included in meta-analysis were sponsored by Pharmaceutical Manufacturing Company. This might cause publication bias for these results and lead to a decrease in the reliability of our results. 


\section{CONCLUSION}

Based on the finding of this meta-analysis, LAMAs did not increase cardiovascular risk in patients with COPD compared with placebo. Also, LAMAs play a pivotal role in improving lung function, dyspnea, and health status, and reducing the incidence of exacerbation in patients with COPD.

Acknowledgements The authors gratefully acknowledge all the authors who shared the results of the included studies, the support of the Lanzhou University First Affiliated Hospital, (Lanzhou, China), and the First Clinical Medical College of Lanzhou University.

Contributors $\mathrm{JL}, \mathrm{CCZ}$ and $\mathrm{MZ}$ conceived and designed the experiments. $\mathrm{CCZ}, \mathrm{MZ}$ and $\mathrm{YW}$ performed the experiments. YW, $\mathrm{HX}$ and $\mathrm{QH}$ analyzed the data. TS, YW and QH contributed reagents/materials/analysis tools. CCZ, MZ and $\mathrm{HX}$ wrote the paper.

Funding This study was supported by the Science and Technology Projects of Gansu Province (grant number 18JR3RA344). The authors remain independent of any funding influence.

\section{Competing interests None declared.}

Patient consent for publication Not required.

Provenance and peer review Not commissioned; externally peer reviewed.

Supplemental material This content has been supplied by the author(s). It has not been vetted by BMJ Publishing Group Limited (BMJ) and may not have been peer-reviewed. Any opinions or recommendations discussed are solely those of the author(s) and are not endorsed by BMJ. BMJ disclaims all liability and responsibility arising from any reliance placed on the content. Where the content includes any translated material, BMJ does not warrant the accuracy and reliability of the translations (including but not limited to local regulations, clinical guidelines, terminology, drug names and drug dosages), and is not responsible for any error and/or omissions arising from translation and adaptation or otherwise.

Open access This is an open access article distributed in accordance with the Creative Commons Attribution Non Commercial (CC BY-NC 4.0) license, which permits others to distribute, remix, adapt, build upon this work noncommercially, and license their derivative works on different terms, provided the original work is properly cited, an indication of whether changes were made, and the use is non-commercial. See: http://creativecommons.org/ licenses/by-nc/4.0/.

\section{ORCID iD}

Jian Liu http://orcid.org/0000-0002-1825-571X

\section{REFERENCES}

1 Global Initiative for Chronic Obstructive Lung Disease (GOLD) [database on Internet]. Global strategy for the diagnosis, management, and prevention of chronic obstructive pulmonary disease, 2021. Available: http://goldcopd.org [Accessed 17 Nov 2020].

2 Lozano R, Naghavi M, Foreman K, et al. Global and regional mortality from 235 causes of death for 20 age groups in 1990 and 2010: a systematic analysis for the global burden of disease study 2010. Lancet 2012;380:2095-128.

3 Mathers CD, Loncar D. Projections of global mortality and burden of disease from 2002 to 2030. PLoS Med 2006;3:e442.

4 Melani AS. Long-acting muscarinic antagonists. Expert Rev Clin Pharmacol 2015;8:479-501.

5 American Thoracic Society 2018 International Conference. American thoracic Society 2018 International Conference. Am J Respir Crit Care Med 2018;197.

6 Singh S, Loke YK, Enright PL, et al. Mortality associated with tiotropium mist inhaler in patients with chronic obstructive pulmonary disease: systematic review and meta-analysis of randomised controlled trials. BMJ 2011;342:d3215.

7 Verhamme KMC, Afonso A, Romio S, et al. Use of tiotropium Respimat Soft Mist Inhaler versus HandiHaler and mortality in patients with COPD. Eur Respir J 2013:42:606-15.

8 Dong $\mathrm{Y}-\mathrm{H}$, Lin H-H, Shau W-Y, et al. Comparative safety of inhaled medications in patients with chronic obstructive pulmonary disease: systematic review and mixed treatment comparison meta-analysis of randomised controlled trials. Thorax 2013:68:48-56.
9 Celli B, Decramer M, Kesten S, et al. Mortality in the 4-year trial of tiotropium (UPLIFT) in patients with chronic obstructive pulmonary disease. Am J Respir Crit Care Med 2009;180:948-55.

10 Gershon A, Croxford R, Calzavara A, et al. Cardiovascular safety of inhaled long-acting bronchodilators in individuals with chronic obstructive pulmonary disease. JAMA Intern Med 2013;173:1175-85.

11 Matera MG, Page CP, Calzetta L, et al. Pharmacology and therapeutics of bronchodilators revisited. Pharmacol Rev 2020;72:218-52.

12 Singh S, Loke YK, Furberg CD. Inhaled anticholinergics and risk of major adverse cardiovascular events in patients with chronic obstructive pulmonary disease. JAMA 2008;300:1439-50.

13 Michele TM, Pinheiro S, lyasu S. The safety of tiotropium-the FDA's conclusions. N Engl I Med Overseas Ed 2010;363:1097-9.

14 Tashkin DP, Celli B, Senn S, et al. A 4-year trial of tiotropium in chronic obstructive pulmonary disease. $N$ Engl I Med Overseas Ed 2008;359:1543-54

15 Wise RA, Chapman KR, Scirica BM, et al. Effect of aclidinium bromide on major cardiovascular events and exacerbations in high-risk patients with chronic obstructive pulmonary disease. JAMA 2019;321:1693-701.

16 Zhou Y, Zhong N-S, Li X, et al. Tiotropium in early-stage chronic obstructive pulmonary disease. N Engl J Med 2017;377:923-35.

$17 \mathrm{Ni} \mathrm{H}$, Soe Z, Moe S. Aclidinium bromide for stable chronic obstructive pulmonary disease. Cochrane Database Syst Rev 2014;64 Suppl IV:Cd010509.

18 Karner C, Chong J, Poole P, et al. Tiotropium versus placebo for chronic obstructive pulmonary disease. Cochrane Database Syst Rev 2014;104:Cd009285.

19 Barr RG, Bourbeau J, Camargo CA, et al. Inhaled tiotropium for stable chronic obstructive pulmonary disease. Cochrane Database Syst Rev 2005:Cd002876.

20 Moher D, Liberati A, Tetzlaff J, et al. Preferred reporting items for systematic reviews and meta-analyses: the PRISMA statement. BMJ 2009;339:b2535.

21 Song F, Gilbody S. Bias in meta-analysis detected by a simple, graphical test. increase in studies of publication bias coincided with increasing use of metaanalysis. BMJ 1998;316:471.

22 Lau J, loannidis JPA, Terrin N, et al. The case of the misleading funnel plot. BMJ 2006;333:597-600.

23 LaForce C, Feldman G, Spangenthal S, et al. Efficacy and safety of twice-daily glycopyrrolate in patients with stable, symptomatic COPD with moderate-tosevere airflow limitation: the GEM1 study. Int I Chron Obstruct Pulmon Dis 2016;11:1233-43

24 Wang C, Sun T, Huang Y, et al. Efficacy and safety of once-daily glycopyrronium in predominantly Chinese patients with moderate-to-severe chronic obstructive pulmonary disease: the GLOW7 study. Int I Chron Obstruct Pulmon Dis 2015;10:57-68.

25 Lee SH, Lee J, Yoo KH, et al. Efficacy and safety of aclidinium bromide in patients with COPD: a phase 3 randomized clinical trial in a Korean population. Respirology 2015;20:1222-8.

26 Rennard SI, Scanlon PD, Ferguson GT, et al. Accord COPD II: a randomized clinical trial to evaluate the 12-week efficacy and safety of twice-daily aclidinium bromide in chronic obstructive pulmonary disease patients. Clin Drug Investig 2013;33:893-904.

27 Kerwin E, Hébert J, Gallagher N, et al. Efficacy and safety of NVA237 versus placebo and tiotropium in patients with COPD: the GLOW2 study. Eur Respir J 2012:40:1106-14.

28 Jones PW, Singh D, Bateman ED, et al. Efficacy and safety of twice-daily aclidinium bromide in COPD patients: the ATTAIN study. Eur Respir J 2012:40:830-6.

29 Jones PW, Rennard SI, Agusti A, et al. Efficacy and safety of once-daily aclidinium in chronic obstructive pulmonary disease. Respir Res 2011;12:55.

30 D'Urzo A, Ferguson GT, van Noord JA, et al. Efficacy and safety of once-daily NVA237 in patients with moderate-to-severe COPD: the GLOW1 trial. Respir Res 2011;12:156

31 Bateman ED, Tashkin D, Siafakas N, et al. A one-year trial of tiotropium Respimat plus usual therapy in COPD patients. Respir Med 2010;104:1460-72.

32 Bateman E, Singh D, Smith D, et al. Efficacy and safety of tiotropium Respimat SMI in COPD in two 1-year randomized studies. Int $J$ Chron Obstruct Pulmon Dis 2010;5:197-208.

33 Johansson G, Lindberg A, Romberg K, et al. Bronchodilator efficacy of tiotropium in patients with mild to moderate COPD. Prim Care Respir J 2008;17:169-75.

34 Criner GJ, Sharafkhaneh A, Player R, et al. Efficacy of tiotropium inhalation powder in African-American patients with chronic obstructive pulmonary disease. COPD 2008:5:35-41.

35 Freeman D, Lee A, Price D. Efficacy and safety of tiotropium in COPD patients in primary care--the SPiRiva Usual CarE (SPRUCE) study. Respir Res 2007:8:45. 
36 Chan CKN, Maltais F, Sigouin C, et al. A randomized controlled trial to assess the efficacy of tiotropium in Canadian patients with chronic obstructive pulmonary disease. Can Respir J 2007;14:465-72.

37 Dusser D, Bravo M-L, lacono P. The effect of tiotropium on exacerbations and airflow in patients with COPD. Eur Respir J 2006;27:547-55

38 Casaburi R, Mahler DA, Jones PW, et al. A long-term evaluation of once-daily inhaled tiotropium in chronic obstructive pulmonary disease. Eur Respir J 2002; 19:217-24.

39 Casaburi R, Briggs DD, Donohue JF, et al. The spirometric efficacy of once-daily dosing with tiotropium in stable COPD: a 13-week multicenter trial. The US tiotropium Study Group. Chest 2000;118:1294-302.

40 Ferguson GT, Feldman G, Pudi KK, et al. Improvements in lung function with nebulized Revefenacin in the treatment of patients with moderate to very severe COPD: results from two replicate phase III clinical trials. J Obstr Pulm Dis 2019;6:154-65.

41 Lipworth BJ, Collier DJ, Gon Y, et al. Improved lung function and patientreported outcomes with co-suspension delivery technology glycopyrrolate/ formoterol fumarate metered dose inhaler in COPD: a randomized phase III study conducted in Asia, Europe, and the USA. Int J Chron Obstruct Pulmon Dis 2018;13:2969-84.

42 Trivedi R, Richard N, Mehta R, et al. Umeclidinium in patients with COPD: a randomised, placebo-controlled study. Eur Respir J 2014;43:72-81.

43 ClinicalTrials.gov. A 52-week, multicenter, randomized, double-blind, parallelgroup, placebo-controlled study to evaluate the safety and tolerability of GSK573719/GW642444 and GSK573719 in subjects with chronic obstructive pulmonary disease (COPD) (COPD nDPI), 2014. Available: https://ClinicalTrials. gov/show/NCT01316887

44 ClinicalTrails.gov. An exercise endurance study to evaluate the effects of treatment of chronic obstructive pulmonary disease (COPD) patients with a dual bronchodilator: GSK573719/GW642444. study a, 2012. Available: https:// ClinicalTrials.gov/show/NCT01328444

45 Martinez FJ, Rabe KF, Ferguson GT, et al. Efficacy and safety of Glycopyrrolate/ Formoterol metered dose inhaler formulated using Co-Suspension delivery technology in patients with COPD. Chest 2017;151:340-57.
46 Celli B, Crater G, Kilbride S, et al. Once-Daily umeclidinium/vilanterol 125/25 Mcg in COPD: a randomized, controlled study. Chest 2014;145:981-91.

47 Donohue JF, Maleki-Yazdi MR, Kilbride S, et al. Efficacy and safety of once-daily umeclidinium/vilanterol 62.5/25 mcg in COPD. Respir Med 2013:107:1538-46.

48 ClinicalTrails.gov. An exercise endurance study to evaluate the effects of treatment of chronic obstructive pulmonary disease (COPD) patients with a dual bronchodilator: GSK573719/GW642444.Study B, 2012. Available: https:// ClinicalTrials.gov/show/NCT01323660

49 Cazzola M, Calzetta L, Matera MG. The cardiovascular risk of tiotropium: is it real? Expert Opin Drug Saf 2010;9:783-92.

50 Tashkin DP, Leimer I, Metzdorf N, et al. Cardiac safety of tiotropium in patients with cardiac events: a retrospective analysis of the UPLIFT@ trial. Respir Res 2015; $16: 65$.

51 Chapman KR, Beck E, Alcaide D, et al. Overall and cardiovascular safety of aclidinium bromide in patients with COPD: a pooled analysis of six phase III, placebo-controlled, randomized studies. J Copd F 2015;3:435-45.

52 Schmiedl S, Fischer R, Ibanez L, et al. Tiotropium Respimat(®) vs. HandiHaler(®): real-life usage and TIOSPIR trial generalizability. Br J Clin Pharmacol 2016;81:379-88

53 Walker S, Fingleton J, Weatherall M, et al. Limited generalisability of UPLIFT findings to clinical practice. Thorax 2013;68:1066-7.

54 Jones PW. St. George's Respiratory Questionnaire: MCID. COPD 2005;2:75-9.

55 Mahler DA, Witek TJ. The MCID of the transition dyspnea index is a total score of one unit. COPD 2005;2:99-103.

56 Ismaila AS, Huisman E, Punekar Y, et al. Comparative efficacy of longacting muscarinic antagonist monotherapies in COPD: a systematic review and network meta-analysis. Int J Chron Obstruct Pulmon Dis 2015; 10:2495-517.

57 Wedzicha JA, Seemungal TAR. Copd exacerbations: defining their cause and prevention. Lancet 2007;370:786-96.

58 Seemungal TA, Donaldson GC, Paul EA, et al. Effect of exacerbation on quality of life in patients with chronic obstructive pulmonary disease. Am J Respir Crit Care Med 1998;157:1418-22. 